\title{
Hemi-Castaing Ligamentoplasty for the Treatment of Lateral Ankle Instability in Young Athletes: About 15 Cases
}

Ismail Kabbaj $^{1{ }^{*}}$, Ghita Salah ${ }^{1}$, Badr Errachid ${ }^{1}$, Reda-Allah Bassir ${ }^{1}$, Moncef Boufettal ${ }^{1}$, Mohamed Kharmaz ${ }^{1}$, Moulay Omar Lamrani ${ }^{1}$, Mohamed Saleh Berrada ${ }^{1}$

${ }^{1}$ Orthopedic Surgery Department of Ibn Sina Hospital, University Mohamed V, Rabat 10100, Morocco

DOI: $10.36347 /$ sjams.2021.v09i04.006

| Received: 28.02.2021 | Accepted: 01.04.2021 | Published: 05.04.2021

*Corresponding author: Ismail Kabbaj

Abstract

Original Research Article

The practice of impact or contact sports often leads to damage to the lateral ligaments of the ankle. Chronic ankle instability accounts for 15 to $25 \%$ of sprain sequelae. Several surgical techniques are described to correct this instability in patients who still present discomfort after rehabilitation. The technique of non-anatomical reconstruction, hemi-Castaing (ligamentoplasty using half of the tendon of the short fibula), is one of the techniques that has been most proven. In this work, we report the results of 15 young athletes who underwent hemi-Castaing ligamentoplasty between 2012 and 2018, with a minimum follow-up of 18 months. We assessed patients according to Olerud and Molander Ankle Score (OMAS), Karlson score (KAFS), and analog visual pain scale (VAS). The functional results were excellent. The patients resumed their sporting activity at the same level, at an average of 3.5 months after surgery and rehabilitation. The stability of the ankle is not affected by the removal of the short fibular transplant.

Keywords: Chronic instability, Hemi-castaing, Ankle, Sprain, Ligament repair.

Copyright $\odot 2021$ The Author(s): This is an open-access article distributed under the terms of the Creative Commons Attribution 4.0 International License (CC BY-NC 4.0) which permits unrestricted use, distribution, and reproduction in any medium for non-commercial use provided the original author and source are credited.

\section{INTRODUCTION}

About 20 to $25 \%$ of patients with a history of acute ankle sprain present chronic lateral instability [1]. However, 20 to $30 \%$ of them who present this recurrent instability and who are embarrassed in daily activities or sports resort to surgery [2]. There are approximately 85 techniques for the repair of lateral ankle instability [3]. They can be divided into three main types: anatomical repairs or direct ligament sutures, nonanatomical (including techniques called tenodesis reconstruction) and techniques using both methods.

The most frequently used tendon for the treatment of chronic ankle instability is the peroneus brevis. In 1984, Castaing used this tendon in its entirety to treat lateral ankle instability [4]. This technique was later modified by using only half of the peroneus brevis which is split in two to perform a tenodesis commonly called Hemi-Castaing and which has the advantage of preserving the stabilizing properties of the peroneus brevis muscle which is the only true eversor of the foot [5].

The aim of this study is to assess the long-term functional outcome in young athletes who have undergone a hemi-Castaing ligamentoplasty for their chronic lateral ankle instability.

\section{Material and Methods Serie's Description}

This is a retrospective cohort study of 15 young patients, practicing different sports (football, basketball, handball and gymnastics) who underwent ligamentoplasty using the Hemi-Castaing technique between 2012 and 2018 for their lateral chronic ankle instability. The surgery concerned the right ankle in 9 cases and the left ankle in 6 cases. The minimum follow-up was 18 months. Patient assessment was based on the Karlson, Olerud and Molander Ankle Score, visual analogue pain scale (VAS) as well as their recovery from sports to the same level as before the procedure. Anteroposterior and lateral radiographs and dynamic projections of the ankle by the TELOS system were also based on when necessary.

\section{Surgical Technique}

A curvilinear retromalleolar incision of $7 \mathrm{~cm}$ in length was made on the outer side of the ankle centered at the top of the lateral malleolus (Figure-1). The fibular tendon sheath is identified and dissected. The peroneus 
brevis tendon is more anterior and deeper than the peroneus longus tendon. To reduce the scarring impact, a second $2 \mathrm{~cm}$ stepped incision is used. It has a dual interest: functional on the one hand in this friction zone and aesthetic on the other. The muscular body of the peroneus brevis is anchored to that of the peroneus longus to strengthen its action (Figure 2 and 3). The tendon of the peroneus brevis is incised longitudinally in half, forming two hemi-tendons of the same diameter at the upper end of the first skin incision. The anterior hemi-tendon is then severed forming an $8 \mathrm{~cm}$ long cord, which is still anchored at its distal insertion at the base of the fifth metatarsal (Figures 4 and 5). A tunnel is then dug in the distal part of the lateral malleolus under fluoroscopic control (Figures 6 and 7) and the transplant is introduced into this tunnel then sutured on itself on an ankle at $90^{\circ}$, in neutral pronosupination until the obtaining of an optimal tension (Figure 8 and 9). The fibular sheath is sutured as well as the subcutaneous and cutaneous plane and the ankle is immobilized in a splint for 30 days.

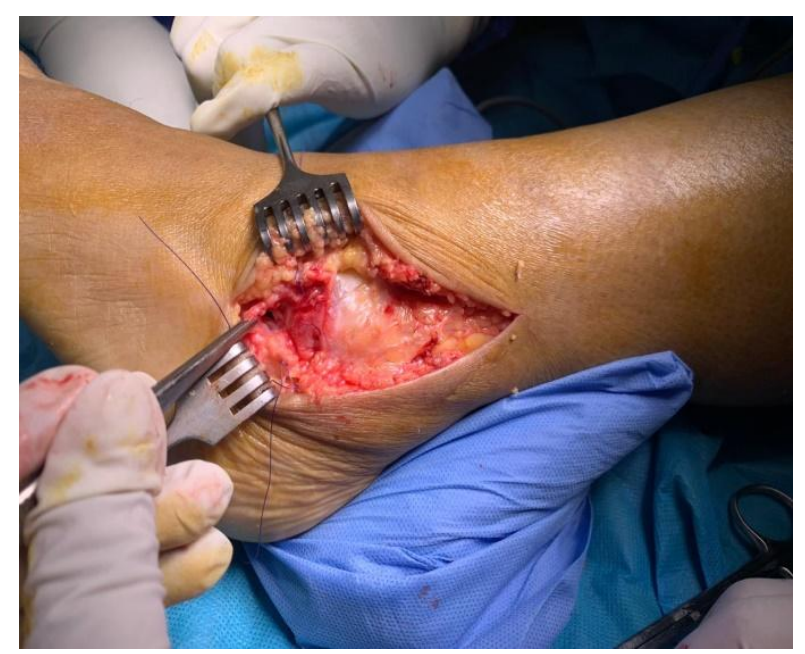

Fig-1: Curvilinear retromalleolar incision on the outer side of the ankle

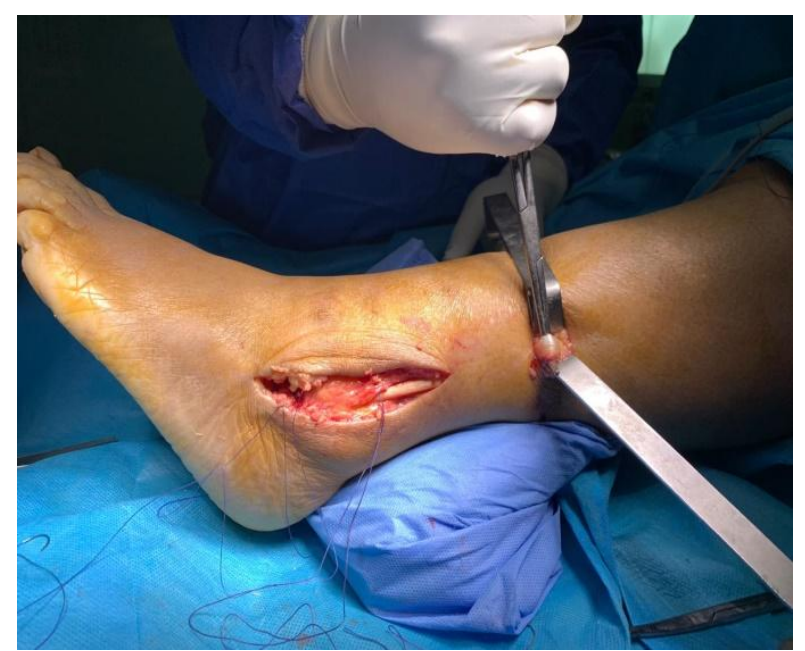

Fig-2: Second incision and muscular body of the peroneus brevis anchored to that of the peroneus longus

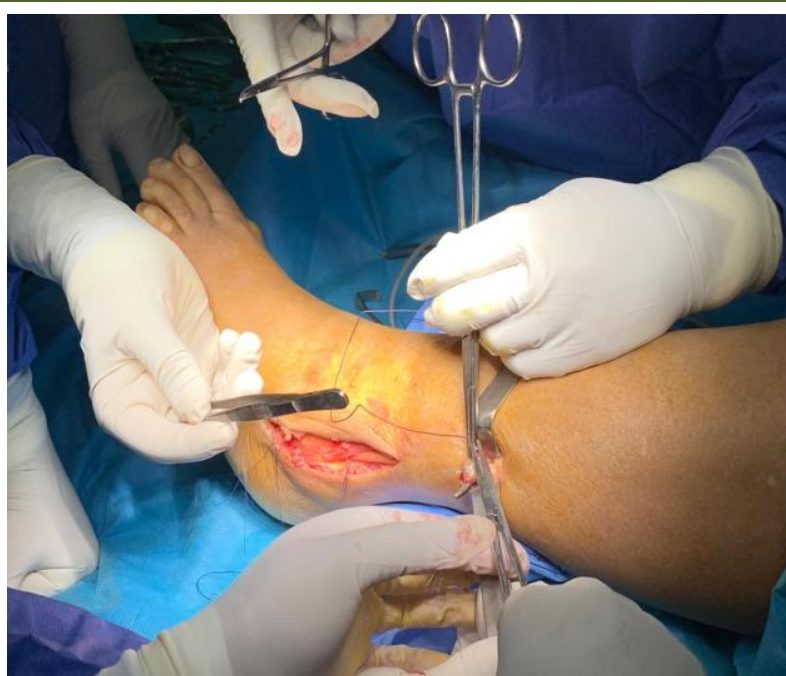

Fig-3: Second incision and muscular body of the peroneus brevis anchored to that of the peroneus longus

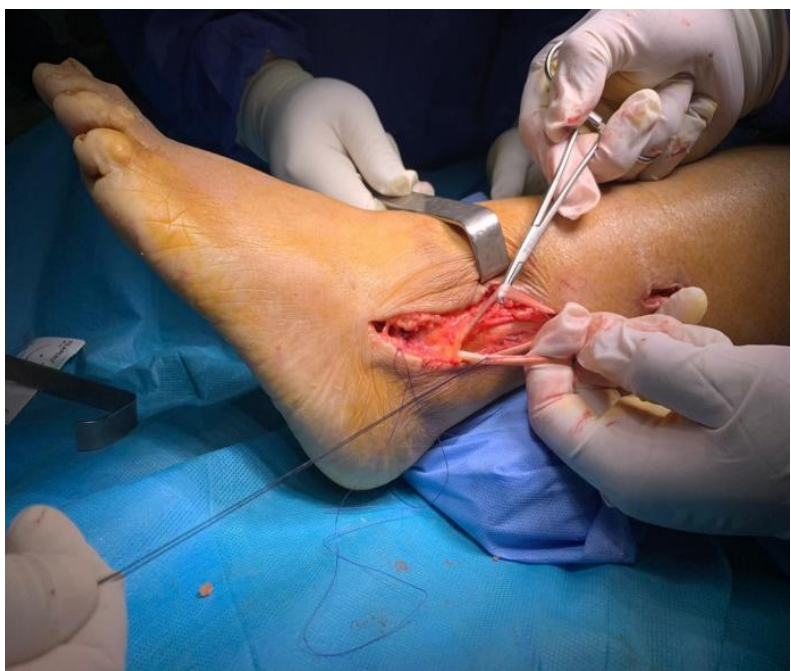

Fig-4: Tendon of the peroneus brevis incised longitudinally in half, forming two hemi-tendons of the same diameter

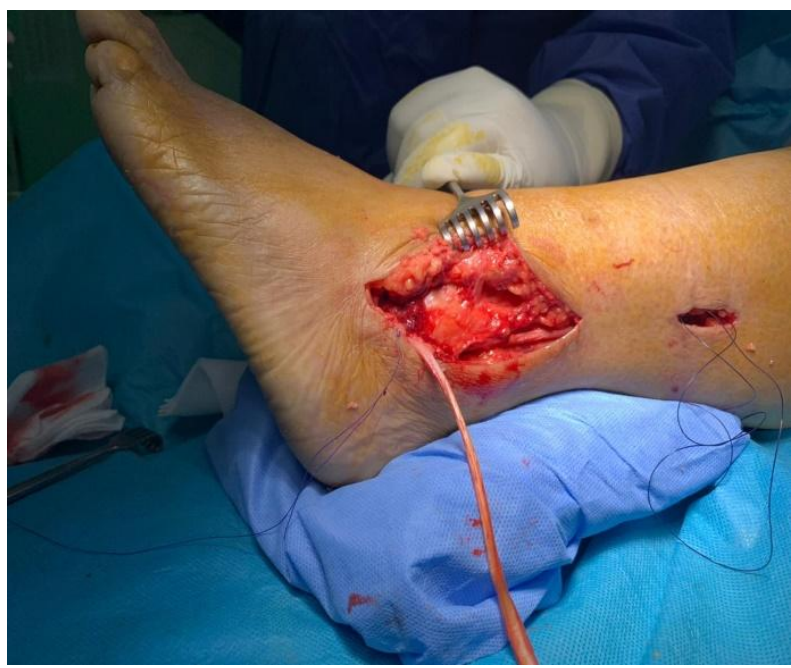

Fig-5: Anterior hemi-tendon of peroneus brevis still anchored at the base of the fifth 


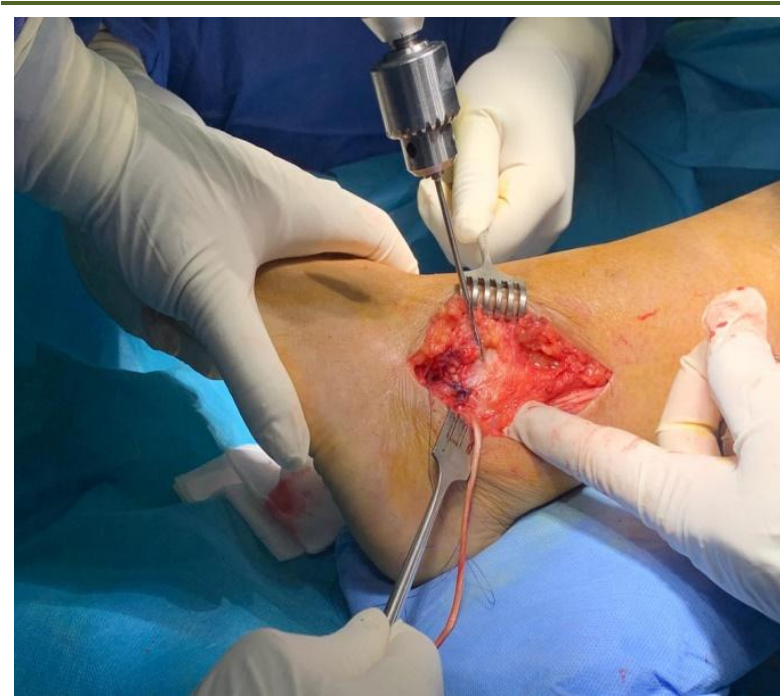

Fig-6: A tunnel dug in the distal part of the lateral malleolus under fluoroscopic control

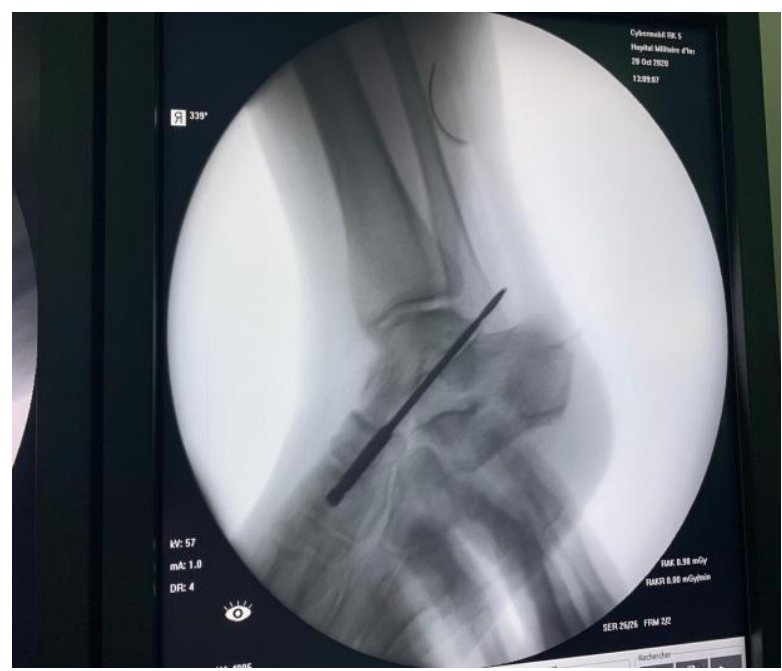

Fig-7: A tunnel dug in the distal part of the lateral malleolus under fluoroscopic control

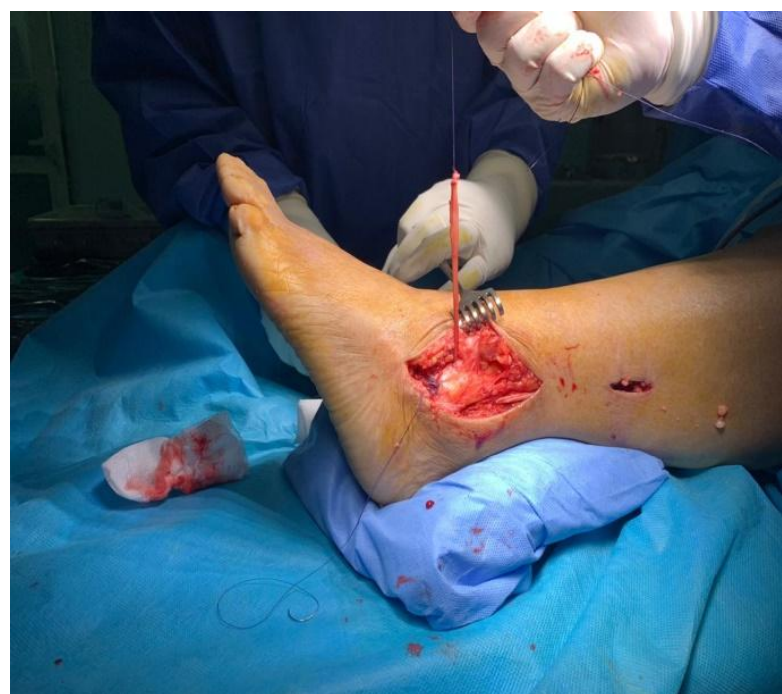

Fig-8: Transplant introduced into the tunnel and then sutured on itself metatarsal

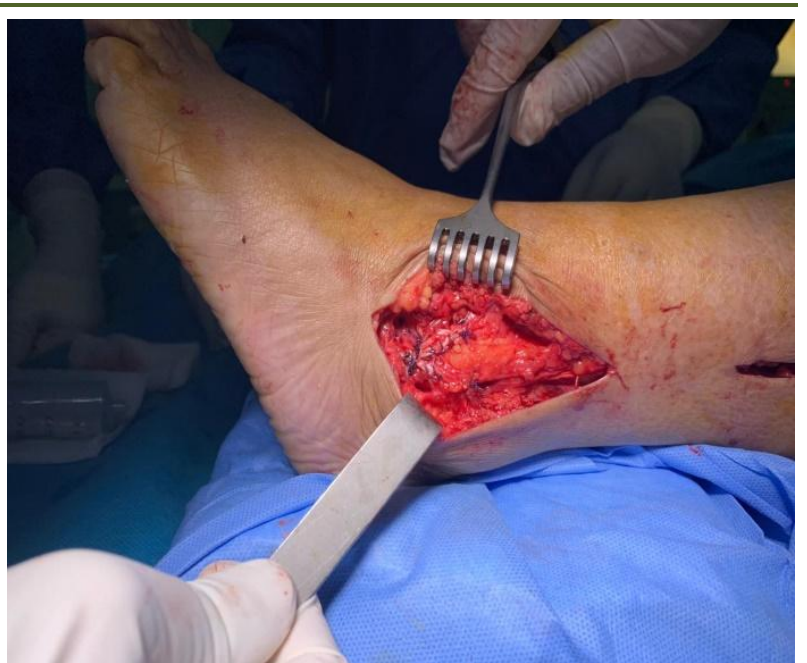

Fig-9: Transplant introduced into the tunnel and then sutured on itself metatarsal

\section{RESULTS}

After removal of the splint, a rehabilitation and physiotherapy program was prescribed for all patients. All the patients were reviewed with a mean follow-up of 23 months. There were 10 men and 5 women. The average number of recurrent sprains before surgery was 13. Patients resumed their sports activities at the same level, at an average of 3.5 months. The functional results were excellent, as all patients were satisfied with the postoperative progress. Only one patient had slight residual pain.

The mean Karlson score was 90 points with 12 patients having an excellent score (score> 80) and 3 having an average score (score between 60 and 80). The OMAS was 91 points with 13 patients having an excellent score $(>80)$, and 2 patients having an average score (between 60 and 80). No patient had a bad outcome (score <60). The pain VAS was 1 while it was 0 for the contralateral side. For radiological evaluation, forced varus $\mathrm{x}$-rays of the ankle showed a mean preoperative angulation of 18.5 degrees and a mean postoperative angle of 4.7 degrees. No case of osteoarthritis of the tibial-talar joint was observed. No patient presented signs of osteoarthritis of the subtalar joint on $\mathrm{x}$-rays taken at a distance from the operation.

\section{DISCUSSION}

Of the many techniques used to treat lateral ankle instability, the hemi-castaing technique is relatively rare to be described. In the other direction, there are many studies that have analyzed the technique of Castaing.

Thus Mabit et al., obtained a good to excellent result in $71 \%$ of cases [6] While in the study by Cañadell et al., where all patients were followed for 2 years and 4 months, $93 \%$ of patients were fully satisfied 
with the result [7]. These results, which are poorer than those of other non-anatomical reconstruction techniques, can be explained by the sacrifice of the fibular short. This is how the Hemi-Castaing technique offers the advantage of respecting the role of the peroneus brevis in eversion and plantar flexion. [8] The stabilization resulting from this ligamentoplasty also has the functional advantage, over other techniques, of being equally effective on the subtalar joint [9].

Some studies have been found, applying this technique, in the literature and we can find an AOFAS (American Orthopedic Foot and Ankle Society) score of 82 points on average and $92 \%$ excellent results (AOFAS) to $93 \%$ of excellent results (Karlson) [5-10].

The functional results of our series are comparable with the results of the literature with nonanatomical techniques, as well as anatomical or reconstruction, with the advantage that in direct repair it is often difficult to locate the healthy extremity or it there is not enough tissue to repair it $[11,12]$.

The rate of patients returning to sport at the same level was equivalent with anatomical techniques with an average of 3 and a half months in our series. The stiffening of the subtalar joint, sometimes implicated in ligamentoplasties, did not appear to be a factor limiting the resumption of sports. Indeed, the sports recovery of our series is comparable to that of all ankle stabilization techniques, whether anatomical or not.

Also, among the postoperative complications noted in the Hemi-Castaing technique, it is noted in addition to the recurrence of instability and residual pain, cases of Achilles tendinitis, algodystrophy.

Lateral saphenous nerve neuroma and dysesthesia of the lateral edge of the foot [13]. With the surgical technique described above, and in our series of patients, only one patient had residual pain postoperatively, while no further complaints were reported from the other patients.

\section{Conclusion}

Along with other anatomical reconstruction techniques, the Hemi-Castaing technique is an important tool to have in the therapeutic arsenal of lateral ankle instabilities, particularly in sports subjects. Its safe and effective nature allows excellent results to be obtained without altering the proprioceptive capacities of the ankle. Certain tips, such as modifying the size of the incision in the first approach, make it possible to reduce its invasiveness on the tendon and scar plan while maintaining its effectiveness.

\section{REFERENCES}

1. Broström L. Sprained ankles. 3. Clinical observations in recent liga-ment ruptures. Acta Chir Scand. 1965; 130(6): 560-9.

2. Baumhauer JF, O’Brien T. Surgical considerations in the treatment of ankle instability. J Athl Train. 2002; 37:458-462.

3. DiGiovanni BF, Partal G, Baumhauer JF. Acute ankle injury and chronic lateral instability in the athlete. Clin Sports Med. 2004; 23:1-19.

4. Castaing J, Falaise B, Burdin P. Ligamentoplasty using the peroneus brevis in the treatment of chronic instabilities of the ankle. Long-term review. Rev Chir Orthop Reparatrice Appar Mot. 1984;70:653-6.

5. Lorenzo G, Calafiore V. Trattamento chirurgico Secondo Castaing nelle instabilita laterali di caviglia. Acta Orthop Ital. 2009;34:11-4.

6. Mabit C, Tourné Y, Besse JL, Bonnel F, Toullec E, Giraud F, Proust J, Khiami F, Chaussard C, Genty C. Réparations chirurgicales d'instabilité latérale chronique de la cheville: la perspective à long terme. Orthop Traumatol Surg Res. 2010; 96 : 417-423.

7. Cañadell JM, Valenti JR, Martinez A, de Pablos J, Villas C. Chronic lateral instability of the ankle. Arch Orthop Trauma Surg. 1982;99:189-93.

8. Schepers T, Vogels LM, Van Lieshout EM. HemiCastaing ligamentoplasty for the treatment of chronic lateral ankle instability: a retrospective assessment of outcome. Int Orthop. 2011 Dec; 35(12):1805-12.

9. Chen CY, Huang PJ, Kao KF, Chen JC, Cheng YM, Chiang HC, Lin CY. Surgical reconstruction for chronic lateral instability of the ankle. Injury. 2004 Aug 1;35(8):809-13.

10. Solana J, Pons M, Guinot C, Viladot R. Ténodèse du court péronier et capsuloplastie ligamentaire dans l'instabilité chronique de la cheville. Dans: SECOT, Sociedad Espanola de Cirugia Ortopedica y Traumatologia. Séville, Espagne. 2005.

11. Karlsson J, Eriksson BI, Bergsten T, Rudholm O, Sword L. Comparaison des deux reconstructions anatomiques pour l'instabilité latérale chronique de la cheville. Am J Sport Med. 1997; 25: 48-53.

12. Jones AP, Sidhom S, Sefton G: Une technique chirurgicale mini-invasive pour la reconstruction augmentée des ligaments latéraux de la cheville avec du ruban de polyester tissé. J Foot Cheville Surg. 2007; 46: 416-23.

13. Richou J, Henry M, Dubrana F. Évaluation à moyen terme d'une intervention type hémiCastaing dans le traitement de l'instabilité chronique de cheville. J Traumatol Sport. 2007; 24:188-92. 